\title{
APOMIXIA FACULTATIVA EM Smilax fluminensis Steud. (Smilacaceae), ESPÉCIE DIÓICA DE FRAGMENTOS FLORESTAIS, CENTRO OESTE DO BRASIL ${ }^{1}$
}

\author{
Seyla Poliana Miranda Pessoa², Juliana Queiros Moraes ${ }^{3}$ e Celice Alexandre Silva ${ }^{4}$
}

\begin{abstract}
RESUMO - Apomixia facultativa em Smilax fluminensis (Smilacaceae) foi estudada em duas populações naturais de Tangará da Serra, MT. A espécie apresenta inflorescências umbeliformes e flores inconspícuas. Foi avaliado o sistema reprodutivo de indivíduos femininos e masculinos de $S$. fluminensis em três episódios reprodutivos consecutivos, sendo a razão sexual entre esses indivíduos equilibrada. No sistema reprodutivo foi registrada a formação de frutos em todos os tratamentos: Polinização Cruzada (82,16\%), Polinização Aberta (70,30\%) e Apomixia (31,81\%). A maioria dos frutos contados desenvolveu três sementes, e a formação de frutos com quatro sementes foi registrada em ambos os fragmentos florestais. Frutos com uma semente foi registrado em apenas um dos fragmentos, e no tratamento apomítico esse número foi cerca de duas vezes maior, em comparação com os demais tratamentos. As abelhas Halictus hesperus e Tetragona clavipes visitaram flores de ambos os sexos e foram consideradas polinizadoras pela sua frequência e comportamento. A apomixia facultativa de $S$. fluminensis é estratégia reprodutiva vantajosa, pois garante sua reprodução mesmo na ausência de polinizadores.
\end{abstract}

Palavras-chave: Entomofilia; Razão sexual; Sistema reprodutivo.

\section{FACULTATIVE APOMIXIS IN Smilax fluminensis Steud. (Smilacaceae), DIOECIOUS SPECIES OF FOREST FRAGMENT, WEST CENTRAL BRAZIL}

\begin{abstract}
Facultative apomixis in Smilax fluminensis (Smilacaceae) was studied in two natural populations of Tangará da Serra - Mato Grosso State, Brazil. The species presents umbelliform inflorescences and inconspicous flowers. We evaluated the reproductive system of female and male individuals of $\boldsymbol{S}$. fluminensis in three consecutive reproductive episodes, and the sex ratio between male and female individuals was balanced.The formation of fruits was recorded in the reproductive system in all treatments:Cross-pollination (82.16\%), Open pollination (70.30\%) and Apomixis (31.81\%). Most fruits counted developed three seeds. The formation of fruit with four seeds was recorded in both forest fragments. Fruit with one seed was recorded in only one of the fragments and, for the apomictic treatment, that number was about two times higher compared to other treatments. The bees Halictus hesperus and Tetragona clavipes, visited flowers of both sexes, and were considered as pollinators due to their frequency and behavior. Apomixis facultative in $\mathbf{S}$. fluminensis is an advantageous reproductive strategy, since ensures their reproduction in the absence of pollinators.
\end{abstract}

Keywords:Entomophily; Reproductive system; Sex ratio.

\footnotetext{
${ }^{1}$ Recebido em 09.12.2012 aceito para publicação em 15.10.2013.

${ }^{2}$ Programa de Pós-graduação em Ambiente e sistemas de produção agrícola, Universidade do Estado de Mato Grosso, UNEMAT, Brasil. E-mail:<seylapessoa@hotmail.com>.

${ }^{3}$ Programa de Graduação em Ciências Biológicas, Universidade do Estado de Mato Grosso, UNEMAT, Brasil. E-mail:<juliana_queiros.m@hotmail.com>.

${ }^{4}$ Universidade do Estado de Mato Grosso, UNEMAT, Brasil, Departamento de Ciências Biológicas. E-mail:

$<$ celicealexandre645@hotmail.com>.
} 


\section{INTRODUÇÃO}

Smilacaceae é um grupo de monocotiledôneas de distribuição predominantemente tropical e subtropical composto por dois gêneros: Smilax e Heterosmilax (SOUZA; LORENZI, 2008). Smilax é considerado o maior e mais importante gênero dessa família, com aproximadamente 300 espécies e o único gênero com representantes no Brasil (ANDREATA, 1997). É considerado um grupo monofilético e possui sinapomorfias, como: par de gavinhas peciolares, inflorescências umbeladas (JUDD et al., 1999) e anteras biesporangiadas (SOUZA et al., 2005).

Das 32 espécies brasileiras de Smilax, destaca-se Smilax fluminensis Steud., liana dióica que ocorre em vários ambientes, desde áreas fechadas como a Floresta Amazônica até locais abertos como o Pantanal (ANDREATA, 1997). Possui muitos caules que podem atingir de 1 até $6 \mathrm{~m}$ de altura, folhas coriáceas, com bainha e pecíolo sem acúleos, inflorescência do tipo umbela, botões florais elípticos ou ovoides, tépalas com dois verticilos diferentes entre si (POTT; POTT, 1994), flores inconspícuas; a flor feminina apresenta ovário súpero tricarpelar e triovular (SOUZA et al., 2005), com seis estaminódios, filiformes, de tamanhos semelhantes, não ultrapassando a metade do comprimento do ovário; flor masculina com anteras lineares, de mesmo comprimento ou maiores que os filetes; osmóforos e nectários localizados na base das tépalas das flores estaminadas e pistiladas (SOUZA et al., 2005); o fruto é uma baga globosa de coloração alaranjada a preta na maturidade (ANDREATA, 2006).

Smilax fluminensis apresenta vasta ocorrência nos Estados de Roraima, do Pará, da Bahia, de Minas Gerais, do Rio de Janeiro, de São Paulo e os Estados da Região Centro-Oeste, estendendo-se até a Bolívia, Paraguai e Argentina. São conhecidas popularmente como “salsa-parrilha” ou “japecanga” (SOUZA; LORENZI, 2008), sendo de amplo uso na medicina popular desde a mais remota antiguidade (ANDREATA, 1997).

O sistema reprodutivo dos vegetais está associado com as relações entre as flores e seus polinizadores, porque as estruturas florais estão adaptadas para favorecer o transporte do pólen e interceder na ação dos seus vetores (BAWA, 1980). Seu estudo requer conhecimentos dos mecanismos das plantas, desde a antese até a formação de frutos e sementes. Além disso, o conhecimento do sistema reprodutivo das plantas tem sido considerado importante ferramenta em programas de manejo e recuperação de áreas degradadas (PIRATELLI et al., 1998).

A dioicia é um sistema sexual caracterizado pela presença em uma população de indivíduos, que produzem flores exclusivamente estaminadas ou pistiladas (GEBER et al., 1999) e está distribuída em cerca 6\% das espécies de angiospermas de regiões tropicais (RENNER; RICKLEFS, 1995). A razão sexual em plantas dióicas é geralmente próxima de 1:1, mas diferenças significativas em favor de um ou outro sexo são frequentemente observadas em taxa de dióicos tropicais (OPLER; BAWA, 1978). A dioicia tem sido associada a uma produção massiva de flores pequenas e inconspícuas, de colorações claras ou pálidas, polinizadas principalmente por pequenos insetos generalistas, com produção de frutos carnosos e dispersão zoocórica, frequentemente realizada por aves (RENNER; RICKLEFS, 1995).

A apomixia é um tipo de reprodução assexuada em que há formação do embrião sem que haja a união do núcleo espermático do pólen com a oosfera (BASHAW, 1980), ou seja, formação de semente sem que haja singamia (ASKER; JERLIN, 1992). A apomixia pode ser facultativa (a planta produz descendentes tanto de origem sexual quanto de origem apomítica) ou obrigatória (KOLTUNOW et al., 1995). Trata-se de um sistema reprodutivo pouco frequente, encontrado em cerca de $15 \%$ das famílias das angiospermas, presente principalmente nas famílias das Gramineae (Poaceae), Asteraceae e Rosaceae. Na maioria dos casos, está presente em espécies herbáceas perenes, pioneiras, de clima temperado e com ampla distribuição. Apomixia em espécies dióicas é considerada evento relativamente raro (RICHARDS, 1997).

O sistema reprodutivo de Smilax é desconhecido, e as contribuições mais recentes no Brasil com relação a esse gênero compreendem os trabalhos de floras regionais, como: Reserva do Parque Estadual das Fontes do Ipiranga-SP (ANDREATA; WANDERLEY, 1984), Serra do Cipó-MG (ANDREATA; COWLEY, 1987), Ilha do Cardoso-SP (ANDREATA, 1991), Pico das AlmasBA (ANDREATA, 1995), Reserva Ecológica de Macaé de Cima-RJ (ANDREATA, 1996), Flora Fanerogâmica do Estado de São Paulo-SP (ANDREATA, 2003) e Reserva Biológica de Poço das Antas-RJ (ANDREATA, 2006). Também são observados estudos anatômicos

Revista Árvore, Viçosa-MG, v.37, n.6, p.1025-1035, 2013 
(SOUZA et al., 2005) e históricos de usos de Smilax pelos boticários no Mosteiro de São Bento, SP (MEDEIROS et al., 2007).

Com o objetivo de ampliar os conhecimentos de Smilax fluminensis, em adição ao estudo do seu sistema reprodutivo foram registrados o período de floração, a biologia floral e a produção de flores por sexo durante três estações de florescimento, para responder às seguintes questões: (1) Qual a razão sexual dos indivíduos masculinos e femininos nas populações estudadas? (2) Quais os sistemas reprodutivos apresentados pela espécie? (3) Quem são e qual é a frequência dos visitantes florais nas áreas de estudo?

\section{MATERIAL E MÉTODOS}

\section{1. Áreas de estudo}

Os estudos foram realizados no Município de Tangará da Serra, Estado de Mato Grosso, em dois fragmentos florestais e durante três estações de florescimento consecutivas. Espécimes de Smilax fluminensis foram avaliadas no Fragmento Florestal de Mata Ciliar (FFMC) durante os anos de 2008 a 2010 e está localizado próximo ao Córrego São José(14³8’48"S; $\left.57^{\circ} 26^{\prime} 07^{\prime \prime W}\right)$. Esse fragmento florestal possui cerca de 2 ha, é circundado por pastagens e sua fitofisionomia está associada a um curso de água, apresentando árvores predominantemente eretas, que variam em altura e não formam galerias (RIBEIRO; WALTER, 1998). O Fragmento Florestal de Mata Estacional Semidecidual (FFMES) (14 ${ }^{\circ} 39^{\prime} 05^{\prime \prime S}$; 57²5’25"W) foi avaliado durante o ano 2010, possui cerca de 18 ha e está localizado em uma propriedade particular. Nesse fragmento, circundado por pastagens e plantações de soja e milho, a fitofisionomia é caracterizada por árvores predominantemente eretas de diferentes alturas e semicaducifólias (RIBEIRO; WALTER, 1998). Os fragmentos florestais estudados estão distantes entre si aproximadamente $2 \mathrm{~km}$.

O Município de Tangará da Serra apresenta altitude de 423 m e clima tropical chuvoso, quente e úmido. A precipitação média anual é de $1.830 \mathrm{~mm}$, com estiagem de junho a setembro. A temperatura média anual é de $24,4^{\circ} \mathrm{C}$ a $26,1^{\circ} \mathrm{C}$, com umidade relativa do ar de 70 $80 \%$. A vegetação do município apresenta característica de Cerrado e Floresta Amazônica (DALLACORT et al., 2010).

\subsection{Proporção entre os indivíduos masculinos e femininos}

Foram identificados os indivíduos masculinos e femininos em ambos os fragmentos florestais estudados. Todos os indivíduos floridos foram marcados, sexados e numerados. Para evitar a amostragem de indivíduos clonais, foram avaliados indivíduos com pelo menos $3 \mathrm{~m}$ de distância entre si (SILVA, 2007). Para melhor compreensão do sistema reprodutivo de Smilax fluminensis, foram registrados semanalmente, durante o período de floração de 2009 e 2010, em ambos os fragmentos, informações como: o período de floração, o número de inflorescências/ indivíduo, de flores/inflorescência e de flores abertas/ indivíduo/dia.

Material testemunho está depositado no Herbário da Faculdade Santa Úrsula, no Rio de Janeiro e no acervo do Herbário TANG (2520).

\subsection{Viabilidade de pólen}

A viabilidade de pólen foi determinada em cinco botões de cinco indivíduos diferentes, através do uso de carmim acético e análise em microscópio (RADFORD et al., 1974). A receptividade estigmática das flores femininas $(\mathrm{N}=9)$ foi determinada nas fases de préantese, antese e início da senescência com o uso de $\mathrm{H}_{2} \mathrm{O}_{2}$ a 3\% (KEARNS; INOUYE, 1993) e análise em estereomicroscópio.

Os períodos de antese e senescência das flores foram observados em 100 botões, sendo 50 femininos e 50 masculinos, em ambos os fragmentos estudados em 2010. Para tanto, foram coletados ramos floridos, compostos por inflorescências com botões em préantese e mantidos em recipiente com água. As observações foram realizadas em laboratório, a cada 2 h, desde a antese até a senescência das flores.

\subsection{Sistema reprodutivo}

O sistema reprodutivo de $S$. fluminensis foi testado no fragmento FFMC (de 2008 a 2010) em inflorescências femininas $(N=62)$ de cinco indivíduos. Em 2010, no FFMES, em inflorescências ( $\mathrm{N}=68)$ de sete indivíduos. Tratamentos de Polinização Aberta (PAB), Polinização Cruzada (PCR) e Apomixia (APO) foram realizados. Inicialmente, foram marcadas as inflorescências ainda em botões e isoladas em sacos de tecido do tipo “organza”, exceto em inflorescências tratadas para a

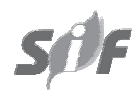

Revista Árvore, Viçosa-MG, v.37, n.6, p.1025-1035, 2013 
PAB; estas tiveram apenas seus pedicelos marcados, para avaliar a eficiência da polinização natural. Nas inflorescências femininas isoladas e em antese, realizou-se o tratamento de PCR, transferindo o pólen de flores masculinas ao estigma das flores femininas que, posteriormente, permaneceram isoladas até a senescência ou a formação de frutos. Para o tratamento de APO, as inflorescências marcadas permaneceram isoladas até a frutificação ou a queda das flores.

A análise de sementes por fruto de cada tratamento foi realizada em indivíduos de ambos os fragmentos estudados em 2010. Para tanto, foram coletados frutos desenvolvidos, média de 15 frutos por tratamento, sendo neles contado o número de sementes formadas por fruto.

\subsection{Visitantes florais}

As observações dos visitantes florais de $S$. fluminensis foram realizadas durante o dia, nos períodos da manhã e tarde, em ambos os fragmentos florestais. Foram registrados: a frequência, o horário da visita, o comportamento e o tempo de permanência dos visitantes nas flores e o recurso floral coletado (pólen ou néctar). Para identificar os possíveis polinizadores foram avaliados, por meio de observações visuais, entre os visitantes, aqueles que contatavam estigmas ou anteras (SILVA, 2007). No FFMC, as observações foram realizadas durante o pico de floração do ano 2009, em 20 inflorescências de quatro indivíduos femininos e em 16 inflorescências de três indivíduos masculinos. No FFMES, essas observações foram realizadas no ano 2010, em 156 inflorescências de sete indivíduos femininos e em 35 inflorescências de seis indivíduos masculinos. Insetos foram capturados com rede entomológica e conservados em álcool 70\%. Hymenopteros foram identificados por especialista até o menor nível taxonômico possível, com o auxílio de chaves analíticas. Material testemunho está depositado no Museu de Entomologia da Universidade Federal de Viçosa (UFV), Viçosa, MG.

\subsection{Análise estatística}

Todas as análises estatísticas dos atributos florais foram realizadas usando o Programa "General Linear Model”, no software Statistica, versão 5.5 (STATSOFT, 2000). Nas análises de variância foi aplicado o teste One-Way ANOVA (ZAR, 1999).

\section{RESULTADOS}

\subsection{Proporção entre os indivíduos masculinos e femininos}

Embora o número de indivíduos femininos e masculinos, encontrados nos fragmentos florestais estudados seja pequeno, a razão sexual foi equilibrada

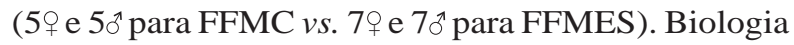
floral - Flores de S. fluminensis são longevas. Em ambos os fragmentos, a antese das flores estaminadas ocorreu durante todo o dia, com pico de abertura entre 16 e $21 \mathrm{~h}$. No momento da antese, as flores já se encontravam liberando pólen e néctar e apresentavam odor suave e adocicado. Cerca de sete dias após o início da antese, as flores começaram a apresentar coloração marromescura, caracterizando o início da senescência floral, e 48 h após o início da senescência foi observada a abscisão das flores.

Nas flores pistiladas, o início da antese e a apresentação do odor e do néctar foram semelhantes com relação às flores estaminadas. Em todas as flores analisadas, a senescência floral iniciou-se cinco dias após o começo da antese, período em que as tépalas e os estigmas adquiriram coloração marrom, das bordas para o centro. A abscisão das flores não fecundadas ocorreu 96 h após o início da senescência.

\subsection{Fenologia}

A floração de $S$. fluminensis nos dois fragmentos e durante os três episódios reprodutivos estudados iniciou-se no final de agosto (estação seca), com pico de floração na segunda quinzena de setembro (estação seca). O final da floração ocorreu na última semana de outubro (início da estação chuvosa). As flores masculinas iniciaram a floração uma semana antes das femininas, finalizando na mesma época das femininas, e o pico de floração aconteceu simultaneamente nos dois sexos. Flores pistiladas e estaminadas apresentaram semelhanças no tamanho, na forma e na coloração.

O fragmento florestal de mata ciliar (FFMC) não apresentou diferença significativa na produção média de inflorescência por indivíduo $\left(\mathrm{F}_{(1,6)}=0,52 ; \mathrm{P}=0,49\right)$ e de flores por inflorescência $\left(F_{(1,6)}=0,72 ; \mathrm{P}=0,42\right)$. O número de flores abertas por indivíduo/dia foi significativamente diferente entre os indivíduos femininos e masculinos desse fragmento $\left(F_{(1,6)}=5,76\right.$; $\mathrm{P}=0,05$, Tabela 1$)$. Houve similaridade no número de inflorescências formadas pelos indivíduos masculinos 
Tabela 1 - Números médios ( $\bar{X}$ ) e desvio-padrão (DP) de inflorescências/Indivíduo, Flores/Inflorescência e Flores/Abertas/ Indivíduo/Dia de Smilax fluminensis Steudel no Fragmento Florestal de Mata Ciliar (FFMC) e no Fragmento Florestal de Mata Estacional Semidecidual (FFMES), no Município de Tangará da Serra, Mato Grosso.Indivíduos (Ind.).

Table 1 - Means ( $\bar{X})$ and Standard Deviation (SD) of inflorescences / Individual, Flowers / Inflorescence and Flowers / Open / individual / day of Smilax fluminensis Steudel in the Riparian Forest Fragment (F.F.M.C.) and in the Semideciduous Forest Fragment (F.F.M.E.S.) in Tangará da Serra, Mato Grosso State. Individuals (Ind.).

\begin{tabular}{|c|c|c|c|c|}
\hline Fragmento (ano)sexos & $\mathrm{N}^{\circ}$ de ind. & $\begin{array}{l}\text { Inflorescências/Ind. } \\
\bar{X} \pm \text { DP }\end{array}$ & $\begin{array}{l}\text { Flores/Inflorescência } \\
\bar{X} \pm \mathrm{DP}\end{array}$ & $\begin{array}{c}\text { Flores abertas/ } \\
\text { Ind./Dia } \pm \text { DP }\end{array}$ \\
\hline \multicolumn{5}{|l|}{ FFMC (2009) } \\
\hline $0^{\pi}$ & 4 & $12,50 \pm 15,02$ & $14,96 \pm 2,98$ & $69,25 \pm 115,23$ \\
\hline 우 & 4 & $8,75 \pm 8,30$ & $18,57 \pm 5,58$ & $35,26 \pm 41,97$ \\
\hline \multicolumn{5}{|l|}{ FFMES (2010) } \\
\hline $0^{\pi}$ & 7 & $15,71 \pm 6,55$ & $16,57 \pm 1,74$ & $177,14 \pm 6,55$ \\
\hline q & 7 & $9,57 \pm 10,18$ & $23,58 \pm 7,76$ & $222,29 \pm 284,30$ \\
\hline
\end{tabular}

e femininos no FFMES $\left(\mathrm{F}_{(1,1)}=1,51 ; \mathrm{P}=0,24\right)$, porém o número de flores por inflorescência $\left(\mathrm{F}_{(1,12)}=7,12\right.$; $\mathrm{P}=0,02)$ e de flores abertas por inflorescência/dia foi significativamente diferente entre os sexos $\left(F_{(1,12)}=4,35\right.$; $\mathrm{P}=0,05$, Tabela 1).

Alta viabilidade do estigma ocorreu desde a préantese e durante todo o período funcional das flores. A viabilidade de pólen também foi alta ( $\bar{X}=91,52 \pm$ 6,19).

\subsection{Sistema reprodutivo}

Os tratamentos realizados para avaliar o sistema reprodutivo de $S$. fluminensis, em ambos os fragmentos florestais e em todos os episódios reprodutivos estudados, resultaram na formação de frutos. A eficiência da polinização aberta (PAB) no FFMC variou substancialmente (de 38 a 317) nos três anos de observação. Houve menor variação na porcentagem de frutos formados no tratamento PCR, no mesmo período e no mesmo fragmento, em comparação com os tratamentos PAB (Tabela 2), sugerindo a limitação de pólen. Além disso, o número de frutos oriundos dos tratamentos de polinização cruzada, realizados no FFMES em 2010, foi significativamente maior $\left(\mathrm{F}_{(1,4)}=9,36, \mathrm{P}=0,03\right)$ quando comparado com as taxas de frutificação dos tratamentos, no mesmo ano, no FFMC.

Todos os tratamentos APO realizados em três anos de observação, e em ambos os fragmentos, resultaram em frutos, indicando que $S$. fluminensis é apomítica, sem a possibilidade de pseudogamia. Aparentemente, a apomixia registrada em $S$. fluminensis é um fato inédito.

\subsection{Frutificação}

A frutificação de $S$. fluminensis iniciou-se na segunda quinzena de outubro, com maturação completa após 30 dias, sendo possível ainda encontrá-la na planta cerca de um ano depois.

Dos 148 frutos contados, resultantes dos tratamentos para avaliar o sistema reprodutivo, a maior parte $(\mathrm{N}=$ 114) apresentou três sementes por fruto, duas e quatro sementes por fruto, registradas em 31 e três frutos, respectivamente. A formação de frutos com uma semente foi observada apenas no FFMES. No tratamento apomítico, esse número foi cerca de duas vezes maior, em comparação com os demais tratamentos (Tabela 3).

\subsection{Visitantes florais}

Flores de $S$. fluminensis foram visitadas por seis ordens de insetos, de diferentes famílias, em 50 h de observação (Tabela 4). A ordem mais diversa em termo de família foi Hymenoptera, e espécimes das demais ordens não foram identificados (Tabela 4). Foi registrado um número de visitas 1,7 vez maior (82 vs. 48) no FFMES, em comparação com o FFMC (Tabela 4). Em ambos os fragmentos florestais estudados, as abelhas Halictus hesperus Smith, 1862 (Halictidae) e Tetragona clavipes Fabricius, 1804 (Apidae) foram responsáveis por 61,53\% das visitas registradas, e o recurso coletado por elas foi néctar e, ou, pólen. O número de visitas dessas abelhas às flores estaminadas e pistiladas foi semelhante (Tabela 4).

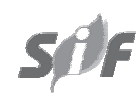

Revista Árvore, Viçosa-MG, v.37, n.6, p.1025-1035, 2013 
Tabela 2 - Resultados das polinizações manuais, in vivo, em flores de Smilax fluminensis Steudel em Fragmento Florestal de Mata Ciliar (FFMC) e em Fragmento Florestal de Mata Estacional Semidecidual (FFMES), no Município de Tangará da Serra, Mato Grosso. PAB= Polinização aberta, $\mathrm{PCR}=$ Polinização cruzada, $\mathrm{APO}=$ Apomixa, $\mathrm{fr}=\mathrm{fruto}$ $\mathrm{fl}=$ flor

Table 2 - Results of manual pollination, invivo, in flowers of Smilax fluminensis Steudel in the Riparian Forest Fragment (FFMC) and in the Semideciduous Forest Fragment (FFMES) in Tangará da Serra, Mato Grosso State. PAB= Open pollination, $P C R=$ Cross-pollination, $A P O=$ Apomixis, $f r=$ fruit and $f l=$ flower

\begin{tabular}{lcccccccr}
\hline & \multicolumn{9}{c}{ FFMC } & \multicolumn{3}{c}{ FFMES } \\
\cline { 2 - 9 } Tratamentos & 2008 & & 2009 & & 2010 & \multicolumn{2}{c}{2010} \\
\cline { 2 - 9 } & $\mathrm{fr} / \mathrm{fl}$ & $\%$ & $\mathrm{fr} / \mathrm{fl}$ & $\%$ & $\mathrm{fr} / \mathrm{fl}$ & $\%$ & $\mathrm{fr} / \mathrm{fl}$ & $\%$ \\
\hline PAB & $317 / 350$ & 90,57 & $63 / 141$ & 44,68 & $38 / 53$ & 71,69 & $260 / 350$ & 74,29 \\
PCR & $31 / 41$ & 75,60 & $35 / 39$ & 89,74 & $42 / 52$ & 80,76 & $425 / 515$ & 82,52 \\
APO & $13 / 18$ & 72,22 & $22 / 121$ & 18,18 & $8 / 75$ & 10,66 & $148 / 565$ & 26,19 \\
\hline
\end{tabular}

Tabela 3 - Percentual (\%), média $(\bar{X})$ e desvio-padrão (DP) de sementes de Smilax fluminensis Steudel, produzidas por tratamentos de polinização aberta (PAB), polinização cruzada (PCR) e apomixia (APO), em fragmento florestal de mata ciliar (FFMC) e em fragmento florestal de mata estacional (FFMES) no Município de Tangará da Serra, Mato Grosso

Table 3 - Percentage (\%), Mean ( $\bar{X})$ and standard deviation (SD) of Smilax fluminensis Steudel seeds produced by open pollination treatments (PAB), cross-pollination (PCR) and Apomixis (APO)in the riparian forest fragment(FFMC) and in the Semideciduous forest fragment (FFMES) in Tangará da Serra, Mato Grosso State.

\begin{tabular}{lccccr}
\hline \multirow{2}{*}{ Tratamentos/local } & \multicolumn{5}{c}{ \% Frutos com } \\
\cline { 2 - 6 } & 1 semente & 2 sementes & 3 sementes & 4 sementes & $\bar{X} \pm$ DP \\
\hline FFMC & - & 23,33 & 73,33 & 3,33 & $2,8 \pm 0,45$ \\
PAB & - & - & 100,00 & - & $3,0 \pm 0,00$ \\
PCR & - & 20,00 & 80,00 & - & $2,8 \pm 0,45$ \\
APO & & & & - & $2,76 \pm 0,56$ \\
FFMES & 5,88 & 11,76 & 82,35 & 6,25 & $2,69 \pm 0,60$ \\
PAB & 6,25 & 18,75 & 68,75 & - & $2,35 \pm 0,67$ \\
PCR & 10,00 & 45,00 & 45,00 & & \\
APO & & & &
\end{tabular}

Tabela 4 - Frequência de visitação de insetos durante o pico de floração de Smilax fluminensis Steudel, em fragmento florestal de mata ciliar (FFMC) e em fragmento florestal de mata estacional semidecidual (FFMES) no Município de Tangará da Serra, Mato Grosso.

Table 4 - Frequency of insects visitation to Smilax fluminensis Steudel flowers in the riparian forest fragment (FFMC) and in the of semideciduous forest fragment (FFMES) in Tangará da Serra, Mato Grosso State.

\begin{tabular}{|c|c|c|c|c|c|c|}
\hline \multirow{2}{*}{ Ordem } & \multirow{2}{*}{ Família/Espécie } & \multirow{2}{*}{$\frac{\text { FFMC }(2009)}{\delta^{\Uparrow}}$} & \multicolumn{3}{|c|}{ FFMES(2010) } & \multirow[t]{2}{*}{ Total/inseto } \\
\hline & & & q & $\sigma^{\pi}$ & q & \\
\hline \multirow[t]{3}{*}{ Hymenoptera } & Halictidae/ Halictus hesperus & 10 & 10 & 16 & 23 & 59 \\
\hline & Apidae/Tetragona clavipes & 8 & 4 & 2 & 3 & 17 \\
\hline & Formicidae & 1 & 2 & 8 & 5 & 16 \\
\hline Lepidoptera & - & 1 & - & - & - & 01 \\
\hline Diptera & - & 2 & 3 & 4 & 5 & 14 \\
\hline Coleoptera & - & 1 & - & 4 & 5 & 10 \\
\hline Hemiptera & - & 1 & - & 1 & 1 & 03 \\
\hline Orthoptera & - & - & 1 & - & 5 & 06 \\
\hline Total & & 24 & 20 & 35 & 47 & 126 \\
\hline
\end{tabular}

Revista Árvore, Viçosa-MG, v.37, n.6, p.1025-1035, 2013 
Durante as visitas, essas abelhas se apresentavam solitárias e pousavam na parte superior das flores, por cerca de 6 a $10 \mathrm{seg}$, contatando os estigmas ou as anteras, comportamento que favorece a polinização cruzada. Essas abelhas forragearam principalmente em dias ensolarados, em diferentes horários do dia, com pico de visitação entre 15 e 17 h, visitando várias flores abertas de uma mesma inflorescência e de um mesmo indivíduo. Devido à frequência e ao comportamento, essas abelhas foram consideradas os principais polinizadores.

Outros insetos visitaram flores de S. fluminensis (Tabela 4), os quais foram menos frequentes e, em suas visitas, não contatavam estigma ou antera. Em muitos casos, o néctar era pilhado pela perfuração das tépalas.

\section{DISCUSSÃO}

As populações estudadas de $S$. fluminensis não diferiram da proporção esperada de 1:1, nas espécies dióicas (OPLER; BAWA, 1978). Essas proporções são de grande utilidade na conservação genética in situ, por indicar o número de indivíduos femininos e masculinos que devem existir em determinada área, escolhida para propósitos conservacionistas (RESENDE et al., 1995). Razões sexuais semelhantes foram observadas em outras espécies dióicas, como: Smilax goyazana (Smilacaceae) (MELO, 2008), Jacaratia spinosa (Caricaceae) (PIRATELLI et al., 1998), Schinus terebinthifolius (Anacardiaceae) (LENZI; ORTH, 2004) e Ilex paraguariensis (Aquifoliaceae) (STURION et al., 1995).

Uma proporção desbalanceada de sexos implica contribuição desigual do número de gametas, favorecendo o sexo mais abundante (ZANON et al., 2009). Além disso, afeta negativamente pela diminuição da diversidade genética da população (HEDRICK, 2000) e redução da produção de sementes (EPPLEY, 2005).

O período de floração das populações estudadas foi inferior a cinco meses e pode ser classificada como anual intermediária (sensu - NEWSTROM et al., 1994). A floração de $S$. fluminensis na estação seca é comum em espécies das florestas neotropicais. Essa estratégia traz vantagens para a planta, por facilitar a ação de agentes polinizadores, pois a chuva pode inibir a atividade de polinização (JANZEN, 1967). Padrão de floração semelhante foi observado em espécies como Duguetia marcgraviana (Annonaceae) (SILVA; DOMINGUES-NETA, 2010), Simarouba amara
(Simaroubaceae) (PINTO, 2005) e Byrsonima sericea (Malphighiaceae) (TEIXEIRA, 2000).

Flores inconspícuas, coloração opaca e a presença de odores semelhantes entre as flores estaminadas e pistiladas, como observado em S. fluminensis, são características frequentes em espécies dióicas tropicais. Segundo Bawa (1980) e Freeman (1997), a tendência de o dimorfismo sexual ocorrer apenas nas estruturas reprodutivas é prevista através da seleção natural para plantas dióicas, garantindo a visitação de insetos polinizadores em ambos os sexos, pois facilita o reconhecimento e evita a discriminação de flores sem recompensa floral pelos agentes polinizadores. A grande longevidade floral registrada em ambos os sexos de S. fluminensis favorece a ação de agentes polinizadores por deixá-las expostas por um longo tempo. Lenza e Oliveira (2006) registraram uma longevidade funcional de seis dias em flores masculinas e femininas de Virola sebifera (Myristicaceae), afirmando que para essa espécie o horário de abertura floral teve papel secundário na polinização de suas flores.

O florescimento masculino antecipado e prolongado, tal como observado em $S$. fluminensis, e outras espécies dióicas como Virola sebifera, Ocotea spixiana (Lauraceae) e Diospiros sericea (Ebenaceae) promoveram um fluxo direcional de pólen de indivíduos masculinos para os femininos (RICHARDS, 1997) e podem aumentar o sucesso reprodutivo da população (PIRATELLI et al., 1998; JARDIM; MOTA, 2007).

O número de flores produzidas entre os sexos florais de $S$. fluminensis ratifica as teorias de Bawa (1983), que afirmou que em espécies dióicas as plantas masculinas geralmente apresentam número maior de flores em comparação com as femininas. A menor produção de flores registrada no fragmento FFMC pode estar relacionada ao tamanho e grau de perturbação desse fragmento e talvez explique a menor taxa de visitação e o menor sucesso reprodutivo registrado nesse fragmento florestal.

Smilax fluminensis apresentou proporção de polens viáveis superior a 90\%, que diferem das características de outras plantas apomíticas que podem apresentar baixa viabilidade de grãos de pólen (RICHARDS, 1997), ou produzir grandes quantidades de polens abortados (VOIGT et al., 2007), resultando em misturas de pólens viáveis e inviáveis depositados sobre o estigma (HÖRANDL, 2010), que podem influenciar no sucesso reprodutivo das espécies.

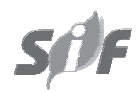

Revista Árvore, Viçosa-MG, v.37, n.6, p.1025-1035, 2013 
Smilax fluminensis apresenta sistema reprodutivo flexível, confirmado pela produção de frutos em todos os tratamentos. A formação de frutos via PCR e PAB demonstra a eficiência dos serviços de polinização e atividade dos polinizadores, que visitam as inflorescências de uma mesma planta ou de outras com frequência, além de assegurar a variabilidade genética das populações (RICHARDS, 1997).

As variações das porcentagens interanuais de frutos formados para o FFMC nos tratamentos PAB e PCR podem ser devidas às mudanças nas condições ambientais e, ou, da atividade dos polinizadores.

A apomixia facultativa tal como registrada em $S$. fluminensis produz dois tipos de sementes férteis: (a) embriões apomíticos geneticamente idênticos ao genótipo materno e (b) embriões zigóticos geneticamente diferentes do genótipo materno (PANGSUBAN et al., 2009), e, dessa forma, a progenie dessas plantas é constituída por uma população variável de plantas, algumas das quais são clones da planta-mãe e outras são hibridos sexuais (KOLTUNOW et al., 1995).

Espécies clonais têm-se apresentado como boa alternativa para início da revegetação de áreas degradadas, devido à conexão morfológica e fisiológica dos clones à planta-mãe e à diferença na distribuição e alocação de recursos, o que permite melhor exploração do substrato (STUEFFER et al., 1996). No caso de S. fluminensis, soma-se a esse fator a independência do agente polinizador para garantir a produção de frutos e sementes, além da manutenção de parte da variabilidade genética pelas plantas oriundas de reprodução sexuada.

Em estudos realizados com espécie de Polygonaceae como Coccoloba cereifera (SILVA et al., 2008) e Asteraceae como Baccharis cylindrica, B. dracunculifolia, Calea hispida, Chromolaena ivaefolia, Taraxacum officinale, Trixis verbasciformis e Vernonia discolor (WERPACHOWSKI, 2004) e plantas forrageiras tropicais com importância econômica de Poaceae dos gêneros Paspalum sp., Panicum sp., Pennisetum sp., Poa sp. e Cenchrus sp., também foi registrada a reprodução por apomixia facultativa (USBERT FILHO, 1981).

Menores taxas de formação de frutos e sementes em testes apomíticos, quando comparados aos de polinização natural e manual, também foram registrados em outras espécies apomíticas de Woonyoungia septentrionalis (Magnoliaceae) (ZENG et al., 2003), Virola sebifera (LENZA; OLIVEIRA, 2006) e Garcinia atroviridis (Clusiaceae) (PANGSUBAM et al., 2009).

A variação do número de sementes por fruto de S. fluminensis nos dois fragmentos florestais estudados pode ser devida a eventos aleatórios como predação de óvulos, qualidade do hábitat ou bases genéticas que controlam a apomixia. Estudos posteriores são necessários para esclarecer essa questão.

Embora o período de floração não tenha sido muito longo, S. fluminensis é uma fonte adicional de recursos para abelhas e outros animais antófilos na estação seca.

Espécies do gênero Halictus têm sido registradas em polinização de plantas silvestres e cultivadas (RAW, 2000; PEARCE et al., 2012). Distância máxima de voo entre recursos e entre locais de nidificação, além de conectividade entre hábitats fragmentados, influencia diretamente a capacidade de dispersão e a variabilidade genética de Meliponineos. Tetragona clavipes tem como característica construir seus ninhos em troncos de árvores vivas (SIQUEIRA et al., 2012), e o hábito trepador de Smilax fluminensis pode caracterizar uma fonte de recurso próximo para essa espécie.

Além disso, uma vez que as populações estudadas tinham os mesmos insetos polinizadores durante os dois anos de observação, os resultados enfatizaram a importância das abelhas nativas Halictus hesperus e Tetragona clavipes na polinização de S. fluminensis e, em especial, a importância da manutenção de pequenas abelhas na polinização de espécies de florestas tropicais.

\section{CONCLUSÕES}

A apomixia facultativa de Smilax fluminensis é fato inédito. Pequenas abelhas nativas realizam a reprodução sexuada, e a maioria dos frutos contados desenvolveu três sementes. Os frutos formados com uma semente, em tratamento apomítico, foi cerca de duas vezes superior quando comparados com os dos demais tratamentos.

\section{AGRADECIMENTOS}

À Regina Helena Potsch Andreata, pela identificação da espécie; ao Professor Anderson Fernandes, pela identificação das abelhas; e à Professora Edenir Maria Serigatto e ao Professor Abílio Luiz Colognese, pelas críticas e sugestões na versão original do manuscrito. 


\section{REFERÊNCIAS}

ANDREATA, R. H. P. Smilacaceae. In: MELO, M.M.R.F.et al. (Ed.) Flora fanerogâmica da Ilha do Cardoso. Caracterização geral da vegetação e listagem das espécies ocorrentes.São Paulo: Instituto de Botânica,1991.p.170-171.

ANDREATA, R. H. P. Smilacaceae. In: STANNARD, B. (Ed.). Flora do Pico das Almas.

Kew:RoyalBotanic Gardens, 1995. p.770-772.

ANDREATA, R. H. P. Smilacaceae. In: LIMA, M. P. M.; GUEDES-BRUNI, R. R. (Org.).Reserva Ecológica de Macaé de Cima, Nova Friburgo, RJ. Aspectos florísticos das espécies vasculares. Rio de Janeiro: Jardim Botânico do Rio de Janeiro,1996.p.433-440.

ANDREATA, R. H. P. Revisão das espécies brasileiras do gênero

SmilaxLinnaeus(Smilacaceae). Pesquisas

Botânica,v.47, n.1, p.5-243, 1997.

ANDREATA, R. H. P. Smilacaceae. In:

WANDERLEY, M. G. L. (Ed.) Flora

fanerogâmica do Estado de São Paulo.

São Paulo: RiMa, 2003. p.323-332.

ANDREATA, R. H. P. Smilacaceae na Reserva Biológica de Poço das Antas, Silva Jardim, Rio de Janeiro, Brasil. Rodriguésia,v.57,n.3, p.647-657, 2006.

ANDREATA, R. H. P.;COWLEY, J. Smilacaceae.In: GIUlietTI, A. M.(Ed.) Flora da Serra do Cipó, Minas Gerais: Caracterização e lista das espécies.São Paulo:Universidade de São Paulo, 1987.p.132.

ANDREATA, R. H. P.; WANDERLEY, M. G. L.Flora fanerogâmica do Parque Estadualdas Fontes do Ipiranga (São Paulo, Brasil):

Smilacaceae.Hoehnea,v.11, n.1,p.114-118, 1984.

ASKeR S.E.;JERLING, L. Apomixis in plants. Boca Raton: CRC Press, 1992. 532p.

BASHAW, E.C. Apomixis and its application in crop improvement. In: FEHR, W. R.; HADLEY, H. H. (Ed.). Hybridization of crop plants.Madison: American Society of Agronomy and Crop Science Society of America, 1980.p.45-63.
BAWA, K. S. Evolution of dioecy in flowering plants. Annual Reviews of Ecology and Systematics, v.11, n.1,p. 15-39,1980.

BAWA, K. S. Patterns of flowering in tropical plants. In:JONES, C. E.; LITTLE, R. J. (Ed.). Handbook of experimental pollination biology.New York: Scientific and Academic,1983. p.394-410.

DALLACORT, R. et al.Aptidão agroclimática do pinhão manso na região de Tangará da Serra, MT. Revista Ciência Agronômica,v.41, n.3, p.373-379, 2010.

EPPLEY, S.M.Spatial segregation of the sexes and nutrientsaffect reproductive success in a dioecious wind-pollinated grass. Plant Ecology, v.181, n.2, p.179-190, 2005.

FREEMAN, C. D. Sexual specialization and inbreeding avoidance in the evolution of dioecy. The Botanic Review, v.63,n.1, p. 65-92, 1997.

GEBER, M.A.; DAWSON, T.E.; DELPH, L.F. Gender and sexual dimorphism in flowering plants. Germany: Springer-Verlag, 1999. 305p.

HÖRANDL, E. The evolution of self-fertility in apomictic plants.Sexual Plant

Reproduction,v.23, n.1, p.73-86, 2010.

HEDRICK, P.W.Genetics of populations. Boston:Jones and Bartlett Publishers, 2000.675p.

JANZEN, D.H. Synchronization of sexual reproduction of trees within the dry season in Central America. Evolution,v.21, n.2, p.620-637, 1967.

JARDIM, M. A. G.;MOTA, C. G. Biologia floral de Virola surinamensis (ROL.) Warb.

(Myristicaceae).Revista Árvore,v.31, n.6,p.1155-1162, 2007.

JUDD, W. S. et al.Plant systematics. A phylogenetic approach.Sunderland:Sinauter Associates,1999. 576p.

KEARNS, C. A.; INOUYE, D. W. Techniques for pollination biologists. Colorado: University Press of Colorado, 1993. 583p.

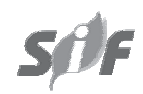

Revista Árvore, Viçosa-MG, v.37, n.6, p.1025-1035, 2013 
KOLTUNOW, A. M.; BICKNELL, R. A.;CHAUDHURY, A. M.Apomixis: Molecular strategies for the generation of genetically identical seeds without fertilization. Plant Physiology, v.108, n.4, p.1345-1352, 1995.

LENZA, E.; OLIVEIRA, P. E. Biologia reprodutiva e fenologia de Virola sebiferaAubl.

(Myristicaceae) em mata mesofítica de Uberlândia, MG, Brasil. Revista Brasileira de Botânica, v.29, n.3, p.443-451, 2006.

LENZI, M.;ORTH, I. A.Fenologia reprodutiva, morfologia e biologia floral de Schinus terebintifollius Raddi (Anacardiaceae), em restinga da Ilha de Santa Catarina, Brasil. Biotemas, v.17, n.2, p.67-89, 2004.

SIQUEIRA, E.L.N.et al. Diversity and nesting substrates of stingless bees (Hymenoptera, Meliponina) in a forest remnant. Psyche, v.2012, n.1, p.1-9, 2012.

SOUZA, V. C.; LORENZI, H.Botânica sistemática: guia ilustrado para identificação das famílias de fanerógamas nativas e exóticas no Brasil, baseado em APG II.São Paulo:

InstitutoPlantarum de Estudos da Flora, 2008. 703p.

MEDEIROS, M. F.;VALLE L. S.; ANDREATA, R. H. P.Histórico e o uso de "Salsaparrilha” (Smilax spp.) pelos boticários no Mosteiro de São Bento.

Revista Brasileira de Biociências,v.5, n.S1, p.27-29, 2007.

MELO, D. M. P. Respostas fotossintéticas e germinação de sementes de Smilaxgoyazana A.D.C. (Smilacaceae).2008. 128 f. Tese (Doutorado em Biodiversidade Vegetal e Meio Ambiente) -Universidade de São Paulo, São Paulo, 2008.

NEWSTROM, L.E.; FRANKIE, G.W.; BAKER, H.G. A new classification for plant phenology based on flowering patterns in lowland tropicalrain forest trees at La Selva, Costa Rica.

Biotropica,v.26, n.2, p.141-159, 1994.

OPLER, P. A.; BAWA, K. S. Sex ratios in tropical florest trees. Evolution,v.32, n.3, p.812-821, 1978.

PANGSUBAN, S.; BAMROONGRUGSA, N.; KANCHANAPOOM, N. C. Facultative apomixis in Garcinia atroviridis (Clusiaceae) and effects of different pollination regimes on reproductive success. Tropical Life Sciences Research,v.20, n.1, p.89-108, 2009.
PEARCE, A.M. et al.Diversity of flower-visiting bees and their pollen loads on a wildflower seed farm in Montana.Journal of the Kansas

Entomological Society, v.85, n.2, p.97-108, 2012.

PIRATELLI, A. J. et al.Biologia da polinização de Jacaratia spinosa (AUBL) ADC.

(CARICACEAE) em mata residual do sudeste brasileiro. Revista Brasileira de Biologia,v.58, n.4, p.671-679, 1998.

PINTO, A. M.et al.Fenologia de Simarouba amara Aubl. na reserva florestal Adolpho Ducke, Manaus, AM. Acta Amazônica,v.35, n.3, p.347-352, 2005.

POTT, A.; POTT, V.J. Plantas do Pantanal. Brasília:Embrapa - SPI, 1994. 105p.

RADFORD, A.E. et al.Vascular plant systematics. New York: Harper e Row,1974. 378p.

RAW, A. Foraging behaviour of wild bees at hot pepper flowers (Capsicum annuum) and itspossible influence on cross pollination. Annals of Botany, v.85, n.4, p.487-492, 2000.

RENNER, S. S.; RICKLEFS, R.E. Dioecy and its correlates in the flowering plants.American Journal of Botany, v.82, n.4, p.596-606, 1995.

RESENDE, M. D. V.; STURION, J. A.; MENDES, S.Genética e melhoramento da ervamate (IlexparaguariensisSt. Hil.). Colombo:EMBRAPA-CNPF, 1995. v.1. p.37-51.

RIBEIRO, J. F.; WALTER, B.M.T. Fitofisionomias do bioma cerrado. In: SANO, S.M.; ALMEIDA, S.P. (Ed.). Cerrado: ambiente e flora.Planaltina: EMBRAPA-CPAC, 1998. p.89-166.

RICHARDS, A.J. Plant breeding systems. Londres: Chapman e Hall, 1997.529p.

SILVA, C. A. Biologia reprodutiva de três espécies distilicas de Psychotria L. e efeitos da fragmentação florestal no sucesso reprodutivo e na diversidade genética $P$. hastisepalaMull, Arg.

(Rubiaceae). 2007. 63 f. Tese (Doutorado em Botânica) - Universidade Federal de Viçosa, Viçosa, MG, 2007. 
SILVA, C. A.et al.Trioecy in Coccoloba cereifera Schwacke (Polygonaceae), a narrow endemic and threatened tropical species Brazilian

Archives Biology and Technology, v.51, n.5, p.1003-1010, 2008.

SILVA, C. A.; DOMINGUES NETA, A. M. Aspectos reprodutivos e visitantes florais de Duguetia marcgraviana Mart. (Annonaceae) na região sudoeste de Mato Grosso. Biotemas, v.23, n.1, p.69-76, 2010.

SOUZA, R. C. O. S.et al. Anatomia e vascularização das flores estaminadas e pistiladas de smilax fluminensis Steudel (smilacaceae). Rodriguésia, v.56, n.2, p.107-121, 2005.

STUEFFER, J. F.; DE KROON, H.; DURING, H. J.Exploitation of environmental heterogeneity by spatial division of labor in a clonal

plant.Functional Ecology, v.10, n.3, p.328334, 1996.

STURION, J. A.; RESENDE, M. D. V.; MENDES, S. Proporção de sexo e efeito sobre a produtividade de biomassa foliar em erva-mate (Ilex paraguariensis St. Hil.). Boletim de Pesquisa Florestal, v.1, n.30-31, p.19-27, 1995.

TEIXEIRA, L. A. G.; MACHADO, I. C. Sistema de polinização e reprodução de Byrsonima Sericea DC (Malpighiaceae). Acta Botânica Brasílica, v.14, n.3, p.347-357, 2000.
USBERT FILHO, J. A.Melhoramento genético e perspectiva de lançamento de cultivares de gramíneas forrageiras no Brasil. Revista Brasileira de Sementes, v.3, n.2, p.135143, 1981.

VOIGT, M.L.et al. Gametogenesis in the apomictic Boecheraholboellii complex: the male perspective. In: HÖRANDL, E., (Ed.)Apomixis: evolution, mechanisms and perspectives. Ruggell, ARGGantner, 2007.p.235-258.

WERPACHOWSKI, J. S.; VARASSIN, I. G.;GOLDENBERG, R. Apomixia e partenocarpia em Asteraceae subtropicais. Revista Brasileira de Botânica,v.27, n.3, p.607-613, 2004.

ZANON, M. L. B.; FINGER, C. A. G.;SCHNEIDER, P. R. Proporção da dioicia e distribuição diamétrica de árvores masculinas e femininas de Araucaria angustifolia (Bertol.) Kuntze, em povoamentos implantados.Ciência Florestal, v.19, n.4, p.425-431, 2009.

ZAR, J.H. Bioestatistical analysis.4.ed.New Jersey: Prentice Hall, 1999. 929p.

ZENG, Q.W. et al. Facultative apomixis in anendangered dioecius species, Woonyoungia septentrionalis Magnoliaceae. Acta Botânica Sinica, v.45, n.1, p.127-173, 2003. 
